\title{
EDUCAÇÃO E PROMOÇÃO EM SAÚDE COMO FERRAMENTA PARA DESMISTIFICAR “FAKE NEWS” SOBRE AS VACINAS CONTRA COVID-19: UM RELATO DE EXPERIÊNCIA
}

\begin{abstract}
Guilherme Bezerra Ferreira1, ORCID ID 0000-0001-9098-2957; Amanda Rodrigues Pereira1, ORCID ID 00000002-9663-6948; Bruno Henryque Marconato', ORCID ID 0000-0001-7113-2463; Gabriela Caroline Laismann Felicetti ${ }^{1}$, ORCID ID 0000-0002-1715-1740; Giovanna de Freitas Ferreira ${ }^{1}$; ORCID ID 0000-0002-6684-2417; Mayra Cleres de Souza ${ }^{1}$, ORCID ID 0000-0002-7520-9592; Luiz Eduardo Alves Costa ${ }^{1}$, ORCID ID 0000-00025900-4407; André Demambre Bacchi², ORCID ID 0000-0002-5330-3721
\end{abstract}

\section{FILIAÇÃO}

(1) Universidade Federal de Rondonópolis, Medical Student

(2) Universidade Federal de Rondonópolis, Medical Student

(3) Universidade Federal de Rondonópolis, Medical Student

(4) Universidade Federal de Rondonópolis, Medical Student

(5) Universidade Federal de Rondonópolis, Medical Student

(6) Universidade Federal de Rondonópolis, Medical Student

(7) Universidade Federal de Rondonópolis, Medical Student

(8) Universidade Federal de Rondonópolis, Professor de Farmacologia e Ensino Tutorial

\section{AUTOR CORRESPONDENTE}

Guilherme Bezerra Ferreira; guilherme.bez@outlook.com; Rua Treze de Maio, № 2957, Apartamento 1, Rondonópolis-MT; Universidade Federal de Rondonópolis.

\section{MENSAGENS-CHAVE}

A falta de informação e as "Fake News" atrapalham a cobertura vacinal de diversas doenças no Brasil, inclusive da COVID-19.

Com orientação adequada e transmissão de conhecimento, as pessoas se sentem mais seguras e dispostas quanto à vacinação.

É necessário que mais ações de educação em saúde sobre vacinação no contexto pandêmico sejam feitas.

\section{RESUMO}

INTRODUÇÃO: Com o surgimento e progressão da pandemia da doença causada pelo vírus SARS-CoV-2 (COVID-19), a busca por vacinas se fez presente. Contudo, a falta de informação e as notícias falsas ("Fake News") influenciam negativamente a vacinação, o que foi intensificado na pandemia. Logo, para informar a população sobre vacinas para COVID19, realizou-se uma ação de educação em saúde com duas frentes. E este relato de experiência aborda as experiências e impressões do grupo desenvolvedor sobre as atividades desenvolvidas e seus impactos. RELATO: Sob supervisão de um docente, e em parceria com a Secretária Municipal de Saúde, foi proposta uma vertente da ação presencial, com abordagem individual de público em praça pública para explicações sobre as vacinas para a COVID-19. Realizou-se, ainda, uma vertente virtual em roda de conversa com estudantes e profissionais da saúde com capacitação desse público para serem disseminadores de conhecimento sobre o tema. DISCUSSÃO: Por ser uma doença nova, as "Fake News" relacionadas a COVID-19 ganham força e aumentam a hesitação da população para vacinar, gerando preocupação na realidade pandêmica. E durante a ação em saúde presencial observaram-se receios da população, que foram esclarecidos, causando uma notável maior segurança e disposição com a vacinação. Ademais, no âmbito da educação permanente em saúde, o público-alvo demonstrou compreensão do conteúdo abordado na capacitação online e disposição a difundi-lo em seus meios de ação. 
CONCLUSÃO: Após análise dos questionários aplicados antes e após cada atividade e do relato verbal dos participantes, conclui-se que a ação "Eu me protejo de notícias falsas e você? Vacine-se" atingiu população e profissionais da saúde, cumprindo o objetivo de orientar e incitar o pensamento crítico, combatendo a desinformação e as "Fake News" relacionadas à vacinação para COVID-19. Então, ficou claro para o grupo, a importância e necessidade de mais ações em saúde nessa temática.

\section{PALAVRAS-CHAVE: Vacinação; Infecções por Coronavírus; Acesso à Informação; Saúde Pública}

\section{ABSTRACT}

INTRODUCTION: With the emergence and progression of the disease caused by the SARS-CoV-2 virus (COVID-19) pandemic, the search for vaccines has been present. However, the Fake News and lack of information negatively affect vaccination, which was intensified in the pandemic. Therefore, to inform population about COVID-19 vaccines, a health education was carried out on two fronts. And this experience report addresses the experiences and impressions of the responsable group on the activities developed and their impacts. REPORT: Under the supervision of a professor, and in partnership with the Municipal Department of Health, an in-person strand of the action was proposed, with individual approach to the public circulating in a square, giving explanations about COVID-19 vaccines. And there was a virtual strand of the action of conversation with students and health professionals, training this audience to be disseminators of knowledge on the subject. DISCUSSION: Because it is a new disease, the Fake News related to COVID-19 gains strength and increases the population's hesitation to vaccinate, generating concern in the pandemic reality. And during the in-person health education, population's doubts were discussed and clarified, generating a remarkable confidence and willingness with vaccination. Furthermore, in the context of permanent health education, the target audience demonstrated understanding of the content covered in online training and a willingness to disseminate it in the environment in which they are inserted. CONCLUSION: After analyzing the questionnaires applied before and after each action and the verbal report of the participants, it is concluded that the action "I protect myself from Fake News and you? Get vaccinated" reached the population and health professionals, fulfilling the objective of guiding and inciting critical thinking, combating misinformation and Fake News related to COVID-19 vaccination. Thus, it was clear to the group the importance and need for more health education on this theme.

\section{KEYWORDS: Vaccination; Coronavirus infections; Access to information; Public health}

\section{INTRODUÇÃO}

Em dezembro de 2019 um novo vírus foi identificado como causador de um surto de pneumonia em Wuhan, China, o SARS-CoV-2. A doença que ele origina, COVID-19, é uma infecção viral transmitida por meio de gotículas respiratórias ou aerossóis de pessoas infectadas. Em 11 de março de 2020, frente a grande quantidade de países com casos de COVID-19, a Organização Mundial da Saúde (OMS) declarou o estado de contaminação como Pandemia ${ }^{1,3}$. Desde então, há uma busca incessante por vacinas que possam controlar a pandemia, reduzindo o número de infectados e de óbitos.

A prevenção de doenças infecciosas através das vacinas aumentou muito a expectativa de vida da população mundial, desempenhando um papel fundamental na estruturação da sociedade atual ${ }^{2}$. Essa necessidade de vacinação, no entanto, muitas vezes não é bem compreendida pela população. No Brasil, a queda da cobertura de vacinas presentes há muito tempo no calendário vacinal é preocupante. Em 2019 e 2020 a meta mínima de imunizações para crianças de idade menor ou igual a 1 ano não foi atingida ${ }^{4}$. Um estudo feito conjuntamente pela Avaaz e pela Sociedade Brasileira de Imunizações $(\mathrm{SBIm})^{5}$ encontrou que as principais razões para não vacinar foram: 1) falta de planejamento ou esquecimento; 2) não entendia a necessidade da vacina; 3) falta de informação; e 4) medo de efeitos colaterais graves. Essas razões sofrem grandes influências decorrentes da disseminação de notícias falsas (Fake News) sobre o tema ${ }^{5.6}$.

Na pandemia, essa realidade, que já era presente na sociedade brasileira, se acentuou. À medida que a pandemia avança, cresce também a desinformação, permeada pelo fenômeno da infodemia, e pela quantidade de Fake News, propagadas principalmente pelas mídias sociais ${ }^{7}$. Com relação à infodemia - definida como o excesso de informações propagadas sobre um determinado tema, sendo verdadeiras ou não, o que torna difícil encontrar uma fonte confiável e quais orientações devem ser seguidas, gerando, assim, um "terreno fértil" para o surgimento e propagação de notícias falsas, que impactam no decorrer da pandemia ${ }^{8}$. O que já se reflete em uma pesquisa publicada pelo IBOPE em agosto de 2020, a qual relatou que cerca de $25 \%$ dos brasileiros não se vacinariam contra a COVID-19, sendo que destes, 3 em cada 10 declararam uma Fake News como razão ${ }^{6}$.

Assim, percebe-se a necessidade de informar corretamente a população e desmentir Fake News acerca das vacinas para COVID-19. Para isso foi planejado uma ação em saúde em duas frentes, uma direcionada aos estudantes e profissionais da saúde, realizada de forma virtual, com o intuito de capacitar profissionais e acadêmicos como disseminadores de conhecimento; e outra direcionada à população geral, realizada de forma presencial em um ponto estratégico do município, com o objetivo de promover a maior adesão à vacinação, divulgar os benefícios da vacinação, apresentar fontes seguras de informação, desmistificar condutas inadequadas e sem comprovação científica e angariar o público e motivar sua participação em campanhas vacinais. 0 presente estudo tem como objetivo relatar as experiências do grupo a respeito das ações desenvolvidas e discutir acerca dos impactos gerados na população e na educação em saúde com profissionais e acadêmicos da área.

\section{RELATO}

Foram reunidos um grupo de estudantes, sob supervisão e aconselhamento de um docente, os quais, inicialmente, buscaram reconhecer as demandas locais quanto à problemática em saúde, e, ao analisar a conjuntura a nível local e o contexto da pandemia do Novo Coronavírus a nível nacional, bem como após realizar diálogo com a Secretaria 
Municipal de Saúde, a qual pontuou a necessidade de uma ação no que tange o incentivo a vacinação, formulouse como objetivo para disseminar conhecimento científico de maneira clara e segura, a ação intitulada "Eu me protejo de notícias falsas e você? Vacine-se", de modo a estimular a adesão popular ao processo de vacinação, bem como desmistificar informações falsas propagandas na comunidade.

Diante da necessidade de abranger um maior contingente populacional em diversos segmentos sociais, foram propostas duas vertentes da ação, uma transcorrendo-se de maneira virtual em roda de conversa com profissionais e acadêmicos ligados a área da saúde, e, posteriormente, outra de forma presencial ao abordar um público mais diverso, em espaço de grande fluxo populacional.

Para consolidar o segmento e execução dessa proposta de ação, firmou-se uma parceria com o Departamento de Ações Programáticas da Secretaria Municipal de Saúde.

Roda de conversa com profissionais e acadêmicos da área da saúde.

Visando atingir um público alvo específico, tal ação buscou capacitar discentes e profissionais da saúde, com ênfase nos Agentes Comunitários de Saúde (ACS), conjecturandose tais profissionais como disseminadores de conhecimento nos territórios adscritos por suas respectivas Unidades Básicas de Saúde (UBS).

A divulgação para tal evento ocorreu primordialmente de maneira virtual por meio de convites compartilhados nas redes sociais Instagram e WhatsApp, sendo que nesse último formalizou-se a construção de um grupo com participação dos acadêmicos de medicina envolvidos no planejamento da ação e os ACS do munícipio, de modo a prestar orientações para inscrição no evento e sanar dúvidas ocasionais sobre o tema proposto. De maneira a promover maior engajamento do público, formalizou-se o incentivo ao divulgar uma certificação para aqueles que participassem do evento.

A roda de conversa ocorreu, então, mediante pré-inscrição formalizada por meio da plataforma Even3 e a apresentação via sítio Google Meet, em dois dias consecutivos com duração de 1 hora e 30 minutos cada, de modo a ampliar a possibilidade de participação sem choque de horário com 0 público de interesse. Tal ação desenvolveu-se por meio da apresentação de casos de Fake News em concomitância a apresentação de palestra expositiva, com posterior abertura para debate e discussão entre os participantes da reunião.

Utilizou-se, ainda, como ferramenta para avaliação de impacto, um questionário pré-teste, o qual continha casos situacionais envolvendo Fake News relacionadas à pandemia do Novo Coronavírus e a sua vacinação. Posteriormente foi aplicado questionário pós-teste com os mesmos casos situacionais, a fim de avaliar se o conhecimento entregue durante o evento foi assimilado de maneira positiva. Ambos os questionários foram realizados por meio da plataforma Google Forms.

Muito embora, a realização de uma atividade virtual possa ser pontuada como aspecto negativo, em fator do distanciamento, a roda de conversa transcorreu-se com bastante troca de conhecimentos e experiências entre o facilitador e os acadêmicos e profissionais da saúde, angariando saberes que permitirão uma propagação na comunidade, além disso a parceria com a Secretária Municipal de Saúde estimulou uma maior adesão dos profissionais atuantes na rede pública.

\section{Ação presencial com a população em geral.}

O planejamento da ação presencial contou com o apoio do Departamento de Ações Programáticas da Secretaria Municipal de Saúde, que forneceu mesas, cadeiras e banners sobre saúde coletiva, bem como auxiliou na divulgação da ação por meio das mídias sociais.

A ação presencial, por sua vez, ocorreu em praça pública, local de grande fluxo populacional, por espaço cedido pela Prefeitura Municipal, e transcorreu-se mediante abordagem individual do público circulante pela praça. Em tal momento aplicava-se um questionário de maneira bastante simplificada para avaliar conhecimentos prévios e disposição para tomar a vacina em tempo hábil, com posterior explicação sobre o tema e contra-argumentos de Fake News, e breve detalhamento da mudança de opinião observado pelo entrevistador para colher informações na avaliação de impacto da ação. Posteriormente, eram oferecidos uma máscara e um Folder contendo as principais informações sobre as vacinas disponíveis contra o Sars-Cov-2 (Figura 1).

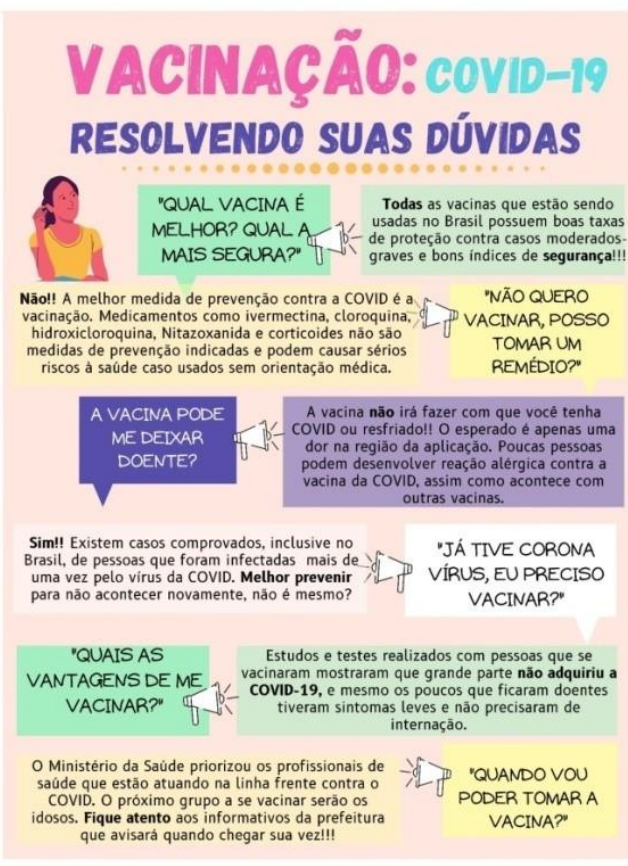

Figura 1. Folder distribuído durante ação em saúde

Aconselhava-se ainda, ao fim da entrevista aconselhava-se, sobre o calendário vacinal contra a COVID-19 de acordo com o plano de vacinação municipal, além de orientar o entrevistado para visitação do ponto de apoio da ação em local 
ventilado e aberto da referida praça, para esclarecimentos com a equipe executora da ação, aferição de pressão arterial e demais orientações da Secretaria Municipal de Saúde.

Durante o evento foi promovido, ainda, a gravação de reportagem por afiliadas regionais de grande emissoras televisivas, a fim de divulgar o evento com maior ênfase, ampliar o público-alvo e disseminar as principais informações da ação para um maior número de indivíduos na região.

Pode-se denotar como aspecto negativo da ação uma impossibilidade de predizer os resultados a longo prazo, isto é, se a atividade de fato surtiu impacto social, contudo, o método de diálogo a partir de abordagem ativa, demonstrou positivamente uma mudança significativa na compreensão comunitária sobre o assunto, o que pôde ser observado por meio da aplicação dos questionários e notas do entrevistador durante e após o diálogo.

\section{DISCUSSÃO}

Pelo fato de a COVID-19 ser uma doença nova, rodeada por incertezas, as notícias inverossímeis, cuja nomenclatura atual é Fake News, ganham espaço e perpassam o cotidiano das pessoas em intervalos cada vez menores, instigadas pelo medo da população e influenciando o comportamento delas. Aliado a isso, grupos sociais que têm acesso limitado aos canais de informação tornam-se mais propensos ao desnorteamento, o que dificulta a deliberação de quais fontes podem ser confiáveis ${ }^{9}$. Dessa maneira, as notícias falsas circuladas nas redes têm aumentado a hesitação da população ao vacinar.

Nesse tocante, a hesitação em vacinar foi apontada pela Organização Mundial da Saúde como um problema global. Nesse sentido, ela define a hesitação à vacina como o atraso ou recusa, apesar da disponibilidade, na administração das vacinas preconizadas ${ }^{10}$. Em consonância a isso, desde 2016, observa-se uma tendência a queda da cobertura vacinal brasileira. Já no ano de 2020, a cobertura vacinal brasileira não ultrapassou 70\%11. São dados preocupantes tanto em relação às doenças que já estavam potencialmente erradicadas no país, como também para a atual realidade pandêmica acarretada pela COVID-19. Ainda no contexto da hesitação vacinal, durante a ação em saúde presencial pôde-se observar receios dos populares em receber a vacina contra o Sars-Cov-2, especialmente pelo medo dos sintomas adversos graves. Tal fato corrobora com estudos que apontaram que o risco de doença evitada por vacina pode ser distorcido ou ressignificado de forma subjetiva, como uma superestimação da frequência ou gravidade dos eventos adversos das vacinas ou subestimação das complicações das doenças que a vacina visa prevenir ${ }^{12}$. Ademais, outros receios, resultados da disseminação de notícias falsas, foi da possibilidade de a vacina alterar o DNA e, ainda, dúvidas sobre a obrigatoriedade do uso da máscara após a vacinação, pois tinham o entendimento que a imunidade seria imediata. Ao final da ação, durante a aplicação do questionário, pôde-se observar a mudança de visão dos entrevistados em relação à eficácia e segurança das vacinas, mostrando-se dispostos a recebê-las e a orientar a comunidade em que estão inseridos.

Ainda, por meio dos questionários aplicados após a roda de conversa, pôde-se observar que os acadêmicos de medicina e os agentes comunitários em saúde municipais demonstraram compreensão das informações ministradas e disposição a difundi-las nos meios em que estão inseridos, proporcionando que a ação pudesse render frutos a médio e longo prazo. Nessa lógica, o combate à antivacinação é constante, e é preciso conscientizar a população que as Fake News sobre a vacina da COVID-19 têm consequências para a saúde pública mundial, ou seja, a liberdade individual não é absoluta quando contraposta às necessidades essenciais das coletividades ${ }^{13}$. Daí a importância dos profissionais de saúde tornarem-se propagadores de informações corretas sobre a vacinação, seus riscos e benefícios. Inclusive, de divulgar de maneira acurada os possíveis efeitos colaterais, antes deles serem utilizados por grupos antivacinas como armas contra a vacinação.

Para o grupo, a ação foi uma oportunidade de exercer pensamento crítico e reflexivo sobre a realidade local para que fosse possível a execução de ações de educação em saúde transformadoras. Dessa forma, essas ações de educação foram praticadas tanto no âmbito da educação permanente em saúde, como política norteadora dos processos educativos contínuos nos diferentes arranjos assistenciais do SUS, capacitando os profissionais de saúde e tornando-os protagonistas e atores sociais do meio em que estão inseridos (14), como também no âmbito da educação popular em saúde, a qual visa incentivar o protagonismo popular, a autonomia e emancipação do sujeito para que ele seja capaz de tomar decisões de saúde para cuidar de si, de sua família e de sua coletividade (15).

\section{CONCLUSÃO}

A ação "Eu me protejo de notícias falsas e você? Vacine-se" foi idealizada e posta em prática de forma a atingir o públicoalvo desejado, correspondendo à população em geral e aos profissionais e acadêmicos da saúde. Tendo como objetivo incitar o pensamento crítico nesse público e orientá-los, estabeleceu-se uma frente de combate às Fake News e à desinformação, uma vez que tais pontos culminam com a desmotivação populacional ao ato de vacinar-se. As educações em saúde do projeto foram percebidas com impacto positivo após análise dos questionários pré e pós atividades.

A realização da ação, não obstante, estimulou nos estudantes envolvidos um exercício prático de comunicação entre profissional de saúde e a população, uma ferramenta primordial para a intervenção no processo saúde-doençaadoecimento do indivíduo e do contexto de saúde comunitária. Ainda, pontua-se como limitação do estudo a impossibilidade de predizer o impacto da ação a longo prazo, ou seja, se o número de vacinados no município realmente aumentou. 
Por fim, percebeu-se que o desenvolvimento de ações em saúde nessa temática deve ser realizado de forma mais rotineira, uma vez que o assunto é de extrema relevância à saúde coletiva e, em especial, diante do contexto de pandemia da COVID-19 e as políticas públicas para seu enfrentamento.

\section{CONFLITO DE INTERESSE}

Os autores declaram que não há nenhum conflito de interesse presente neste artigo.

\section{FINANCIAMENTO}

Os autores declaram que não houve fontes de financiamento.

\section{REFERÊNCIAS}

1. Oliveira LMS, Gomes NP, Oliveira ES, et al. Estratégia de enfrentamento para covid-19 na atenção primária à saúde: relato de experiência em Salvador-BA. Revista Gaúcha de Enfermagem [Internet]. 2021 [cited 2021 May 29]; Available from: https://www.scielo.br/j/rgenf/a/qBvZQPkZRQfCkwcDvN MnwcS/?lang=en\#B1

2. Chung JY, Thone MN, Kwon YJ, et al. Vacinas COVID19: a situação e as perspectivas dos pontos de vista de entrega. Elsevier Public Healt Emergency Collection [Internet]. 2020 Dec 24 [cited 2021 May 29]; Available from:

https://www.ncbi.nlm.nih.gov/pmc/articles/PMC7759095 I.

3. Rego TC, et al. Produtivismo, pesquisa e comunicação científica: entre o veneno e o remédio. Educação e Pesquisa [Internet]. 2014 abril/junho [cited 2021 May 29];40 Available from: https://www.scielo.br/j/ep/a/Y7kSww5RQSQRSs89g3sj $\mathrm{grh} /$ ?lang=pt\&format=pdf

4. Agência Brasil [Internet]. Rio de Janeiro: Valéria Aguiar; 2020 Oct 16 [cited 2021 May 29]. Available from: https://agenciabrasil.ebc.com.br/saude/noticia/202010/em-queda-ha-5-anos-coberturas-vacinaispreocupam-ministerio-dasaude\#: :text=J\%C3\%A1\%20at\%C3\%A9\%202\%20de \%20outubro,59\%25\%20do\%20p\%C3\%BAblico\%2Dalv

5. AVAAZ, Sociedade Brasileira de Imunizações (SBIm). As Fake News estão nos deixando doentes?: Como a desinformação antivacinas pode estar reduzindo as taxas de cobertura vacinal no Brasil [Internet]. online; 2019 novembro [cited 2021 May 29]. Available from: https://sbim.org.br/images/files/po-avaaz-relatorioantivacina.pdf
6. AVAAZ. 1 em cada 4 brasileiros pode não se vacinar contra a COVID-19: IBOPE: Entre estes, 3 em cada 10 (ou 34\%) declaram uma fake news como razão para não se vacinar, como "a vacina pode ter chips implantados para controle da população" [Internet]. online; 2020 Sep 07 [cited 2021 May 29]. Available from:

https://secure.avaaz.org/campaign/po/brasileiros nao v acinar covid/?slideshow

7. Zarocostas J. How to fight an infodemic. Lancet. 2020 Feb 29; 395(10225):676. doi: 10.1016/S01406736(20)30461-X.

8. Organização Pan-Americana da Saúde OPAS. ENTENDA A INFODEMIA E A DESINFORMAÇÃO NA LUTA CONTRA A COVID-19: DEPARTAMENTO DE EVIDÊNCIA E INTELIGÊNCIA PARA AÇÃO EM SAÚDE. Institucional Repository for Information Sharing IRIS [Internet]. 2020 [cited 2021 Jul 7]; Available from: https://iris.paho.org/bitstream/handle/10665.2/52054/Fa ctsheet-Infodemic por.pdf?

9. De Matos, R. C. Fakenews frente a pandemia de COVID-19. Vigilância Sanitária em Debate: Sociedade, Ciência \& Tecnologia (Health Surveillanceunder Debate: Society, Science \& Technology) - Visa em Debate, [S. I.], v. 8, n. 3, p. 78-85, 2020. DOI: 10.22239/2317-269x.01595. Disponível em: .https://doi.org/10.22239/2317-269x.01596

10. WHO - WORLD HEALTH ORGANIZATION. ReportoftheSageworkinggrouponvaccinehesitancy.

Geneva, 1으. 2014 . Disponível em: https://www.who.int/immunization/sage/meetings/2014/ october/1 Report WORKING GROUP vaccine hesita ncy final.pdf

11. SOCIEDADE BRASILEIRA DE IMUNIZAÇÕES. Coberturas vacinais no Brasil são baixas e heterogêneas, mostram informações do PNI. SBIm, 2020. Disponível em: https://sbim.org.br/noticias/1359coberturas-vacinais-no-brasil-sao-baixas-eheterogeneas-mostram-informacoes-dopnih\#: :text=Em\%202020\%2C\%20embora\%20os\%20d ados,e $\% 2055 \% 2 \mathrm{C} 7 \% 25 \%$

12. Siddiqui M, Salmon DA, Omer SB, et al. Epidemiologia da hesitação vacinal nos Estados Unidos. Human vaccines e immunotherapeutics [Internet]. 2013 Dec 01 [cited $2021 \quad$ May 29]; https://dx.doi.org/10.4161\%2Fhv.27243. Available from: https://www.ncbi.nlm.nih.gov/pmc/articles/PMC4162046 l.

13. Gostin LO, Wiley LF, et al. Poderes governamentais de saúde pública durante a pandemia de COVID-19: pedidos de estadia em casa, fechamento de empresas e restrições de viagens. National Library of Medicine: National Center for Biotechnology Information [Internet]. 2020 Jun 02 [cited 2021 May 29];323(21) DOI https://doi.org/10.1001/jama.2020.5460. Available from: https://pubmed.ncbi.nlm.nih.gov/32239184/. 
14. BRASIL. Ministério da Saúde. Secretaria de Gestão do Trabalho e da Educação na Saúde. Departamento de Gestão da Educação na Saúde. Política Nacional de Educação Permanente em Saúde. Portaria № 1.996 GM/MS, 2007‥

15. BRASIL. Ministério da Saúde. Secretaria e Gestão do Trabalho e da Educação na Saúde. Departamento de Gestão da Educação na Saúde. Política Nacional de Educação Permanente em Saúde. Portaria NPORTARIA № $2.761 \mathrm{GM} / \mathrm{MS}, 2013^{\mathrm{a}}$. 